\title{
Status of Wave and Tidal Power Technologies for the United States
}

\section{Technical Report} NREL/TP-500-43240

August 2008

W. Musial 
Status of Wave and Tidal Power Technologies for the United States

W. Musial

Prepared under Task No. WER8.2006
Technical Report NREL/TP-500-43240

August 2008

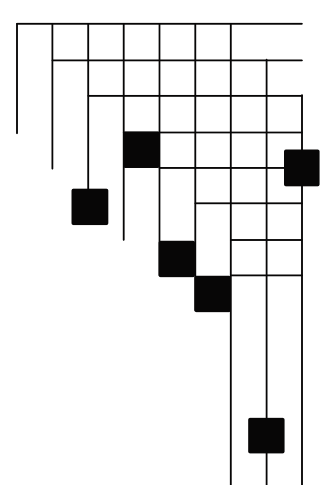




\section{NOTICE}

This report was prepared as an account of work sponsored by an agency of the United States government. Neither the United States government nor any agency thereof, nor any of their employees, makes any warranty, express or implied, or assumes any legal liability or responsibility for the accuracy, completeness, or usefulness of any information, apparatus, product, or process disclosed, or represents that its use would not infringe privately owned rights. Reference herein to any specific commercial product, process, or service by trade name, trademark, manufacturer, or otherwise does not necessarily constitute or imply its endorsement, recommendation, or favoring by the United States government or any agency thereof. The views and opinions of authors expressed herein do not necessarily state or reflect those of the United States government or any agency thereof.

Available electronically at http://www.osti.gov/bridge

Available for a processing fee to U.S. Department of Energy and its contractors, in paper, from:

U.S. Department of Energy

Office of Scientific and Technical Information

P.O. Box 62

Oak Ridge, TN 37831-0062

phone: 865.576 .8401

fax: 865.576 .5728

email: mailto:reports@adonis.osti.gov

Available for sale to the public, in paper, from:

U.S. Department of Commerce

National Technical Information Service

5285 Port Royal Road

Springfield, VA 22161

phone: 800.553 .6847

fax: 703.605.6900

email: orders@ntis.fedworld.gov

online ordering: http://www.ntis.gov/ordering.htm 


\section{Executive Summary}

This paper presents the status of marine applications for renewable energy as of 2008 from a U.S. perspective. The technologies examined include wave, tidal, and ocean current energy extraction devices that are currently being demonstrated in at least one ocean project. The paper also examines the resources for each of these technologies, the limitations to the current assessments, and the research and development needs of the marine renewable energy industry based on the author's experience and opinions. It provides an overview of the National Renewable Energy Laboratory and its capability to meet some of the industry's R\&D needs as a technology integrator and a third party evaluator. The paper concludes that marine energy resources are globally significant and should be developed as part of the diverse clean energy portfolio that will be necessary to reach expected future carbon reduction targets. No single energy source will be able to achieve these reductions independently so many sources must be simultaneously developed. 


\section{Contents}

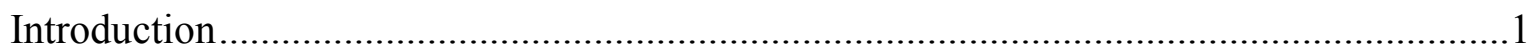

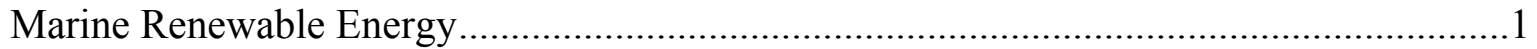

Marine Renewable Energy Resource Estimates .......................................................

Marine Renewable Energy Technology Maturity Path .....................................................3

Overview of Wave and Tidal Power Technologies ........................................................4

Summary of Research and Development Needs ...................................................6

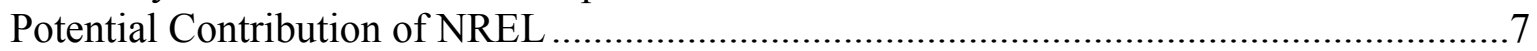

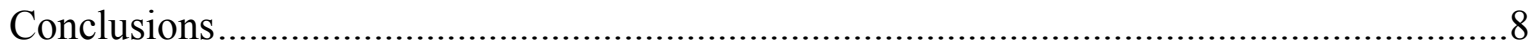

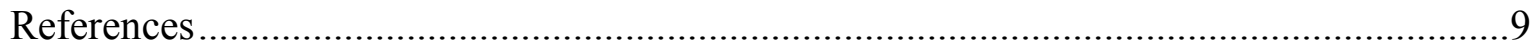

\section{Tables}

Table 1. Wave Resource by Region.............................................................................2

Table 2. Tidal Resource by Region..........................................................................2

Table 3. Resource Comparison of Estimated Energy Extraction Limits (EPRI ref3) ...........3

\section{Figures}

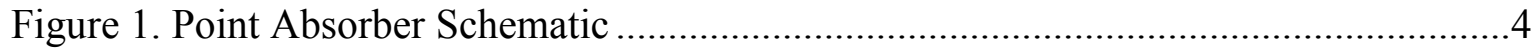

Figure 2. Overtopping Wave Terminator Schematic ................................................4

Figure 3. Oscillating Water Column Wave Terminator Schematic.....................................5 


\section{Introduction}

The world is facing enormous environmental issues as human consumption has begun to stress the Earth's resources and its ability to sustain our existence in the way we are accustomed. The urgency to deploy solutions to climate change is compounded by parallel and equally daunting issues with the depletion of our conventional energy supplies and the accompanying national security issues. New energy sources must be identified and developed as a top priority.

The U.S. Department of Energy's National Renewable Energy Laboratory (NREL) believes that a diverse portfolio of energy solutions is needed to meet our future energy challenge [1]. Meeting the challenge will also require modernization of our energy distribution and use systems, and the development and implementation of energy efficiency technologies that both minimize energy waste and improve energy conversion efficiency. Implementation will take strong leadership and dedicated international cooperation.

\section{Marine Renewable Energy}

A variety of significant untapped renewable energy resources can be found in and around the world's oceans. These resources, which include waves and water currents, are typically located near areas with the highest population densities. In the United States, $78 \%$ of the electricity is used in a state bordering an ocean or a Great Lake [2].

Wind driven waves are incident on every coastline and contain large amounts of concentrated energy potential. Moving water currents include three separate resource categories: Ocean currents, which are the primary ocean water conveyors around the globe on a macro scale; tidal currents, which ebb and flow twice a day through hundreds of inlets and estuaries due to the coupling of lunar gravitation with Earth's axial rotation; and river currents, from which downstream flow provides kinetic energy potential in many river systems without impoundments that are typical of conventional hydroelectric systems. In addition, offshore wind energy is vast

and abundant along the nation's coastlines. In more tropical areas, ocean thermal systems can be deployed for electric generation, desalination, and central cooling. This paper only focuses on wave and water current resources and energy technologies.

\section{Marine Renewable Energy Resource Estimates}

Wave Resource: Generally, wave energy increases with latitude and has greater potential on the west coast of the United States because global winds tend to move west to east across the Pacific Ocean. The total energy contained in the waves is dependent on the linear length of wave crest, the wave height and the wave period. Wave energy resource assessments have been performed by the Electric Power Research Institute (EPRI) and the methods for calculation are well documented $[3,4,5,6,7,8]$. Coastal areas with wave resources below $10-\mathrm{kW} / \mathrm{m}$ were not included in the estimates. 
Table 1 shows the gross wave energy resource by region. This is an estimate of the energy contained in the incident waves if it were converted to electricity.

Table 1 - Wave Resource by Region

\begin{tabular}{lc}
\hline US Wave Resource Regions (>10kW/m) & TWh/yr \\
New England and Mid-Atlantic States & 100 \\
Northern California, Oregon and Washington & 440 \\
Alaska (exclusive of waves from the Bering Sea) & 1,250 \\
Hawaii and Midway Islands & 330 \\
\hline
\end{tabular}

Similarly, Table 2 shows the estimated tidal energy resources for two regions;

Table 2 - Tidal Resource by Region

\begin{tabular}{lc}
\hline US Tidal Resource Region $(1.0 \mathrm{~kW} / \mathbf{m} 2)$ & TWh/yr \\
Alaska & 109 \\
Continental US & 6 \\
\hline
\end{tabular}

Alaska and the continental United States $[9,10,11]$. EPRI summarized these studies in reference 3 .

For ocean currents, the gross energy potential has not been determined for the Gulf Stream [12].

For river currents there has not been a comprehensive analysis of the potential. The best study, conducted by New York University in 1986, examined rivers with discharge rates of $113 \mathrm{~m}^{3} / \mathrm{s}$ and velocities of $1.3 \mathrm{~m} / \mathrm{s}$ [13]. The NYU report estimated the potential at 12,500 MW average power.

An effort to quantify the gross and extractable energy resource for the various ocean energy categories has not yet been tackled on a national or international scale, and there is no well established method of reporting the resource quantities and making comparisons to meaningful energy supply metrics. Tidal resource estimates, based on the aggregate of the best and most characterized sites, are still being evaluated. Many smaller and lower energy sites have not yet been considered, but their inclusion may raise the resource estimates significantly.

Table 3 shows a relative comparison of the potential extractable U.S. ocean renewable resources in terms of annual terawatt-hours. For comparison, the potential for deep water and shallow water offshore wind are included assuming $60 \%$ siting exclusions and $40 \%$ capacity factors. 
Table 3 - Resource Comparison of Estimated Energy Extraction Limits (EPRI ref3)

\begin{tabular}{lc}
\hline \multicolumn{1}{c}{ Energy Source } & TWh/yr \\
Deep Water $>$ 30-m Offshore Wind & 3270 \\
Shallow Offshore Wind & 678 \\
Wave Energy & 252 \\
Tidal Current & 17 \\
Ocean Current (Florida) & 50 \\
In-stream River Current & 110 \\
\hline
\end{tabular}

There is still considerable uncertainty with these energy extraction estimates as they do not account for energy delivery and proximity to the load. For example, a large amount of the resource is located in Alaska, but because of its remote location, it may not be feasible to transmit the power. Also, extraction limits are dependent on device type, siting restrictions due to environmental sensitivities, and alternative use (e.g. fishing). EPRI, which has done the most comprehensive studies to date, estimates that the maximum potential is approximately equal to installed capacity of conventional hydropower [14].

\section{Marine Renewable Energy Technology Maturity Path}

Marine energy is at an early stage of development, and as of this writing, no company has established a fully commercialized system. The current state of this industry can be compared to the early stages of the wind energy industry in that many concepts have been proposed with a wide variety of methods for energy capture and conversion yet with little technology convergence. This technological diversity can be attributed to the nascent state of the industry, which does not have a basis for evaluating different concepts, the standards for design guidance, or the analytical tools for design. Nevertheless, dozens of companies are trying to deploy technology around the world. Recent studies show that success appears more likely when a multi-step progression of development from small-scale model testing in laboratory tanks to open ocean testing is followed [15]. Although a few companies have progressed to single fullscale ocean testing, none of the designs have been adopted by developers and financiers for mass production.

The lessons learned from wind energy's recent commercial success tell us that, even with commercial adoption, the maturity of the industry will require substantial commercial deployment and many years of operating experience before any device can be considered mature. (The wind energy industry deployed its first 1000-MW in California between 1981 and 1985, with over 90,000-MW installed in 2008) To encourage this same level of deployment, aggressive economic incentives will likely be needed; the modest production tax incentives that motivate wind energy deployment today are not likely to work for less mature marine energy systems. Marine energy systems need incentives that will encourage risk and innovation, as well as energy production at this early stage. In addition, regulatory agencies will need to modify the regulations developed for other industries such as hydroelectric dams and oil platforms, to fit the more benign, modular, deployment paradigm of marine renewables. 
Government sponsored incentives in the United States may be necessary to stimulate U.S. marine energy deployment and the economic benefits that follow, but may not be sufficient to mature the technology on its own. However, the marine resource is distributed worldwide and much of the effort thus far has taken place in countries such as the United Kingdom, Ireland, Canada, and Portugal. Therefore, it is important that the United States take an international view of marine energy technology development, collaborating as much as possible with key marine energy nations. The international experience gained will help accelerate technological maturity of the industry as a whole.

\section{Overview of Wave and Tidal Power Technologies}

Marine energy devices are generally classified first by their resource type and next by their method of energy capture. The wave devices that have been demonstrated so far are subdivided into several categories including, point absorbers, attenuators, and two kinds of terminators; overtopping and oscillating water column. Point absorbers and attenuators are installed in the wave field and extract a portion of energy from waves that pass through. Terminators stop the wave, absorbing most of the wave's energy. A small fraction of the energy is reflected back to sea. Because the different types of devices are described in various references $[16,17,4]$, only brief descriptions are provided below.

A point absorber typically comprises a buoyant float that heaves up and down with waves relative to a moored component that is stationary in the heave direction (see Figure 1). Energy generation is associated with this relative motion through a conversion device. Conversion devices can be various forms of linear electric generators, or hoses and pumps that create high fluid pressure to be converted later in a central generating station.

Wave attenuators are very similar in principle, but the energy is captured over a surface area.

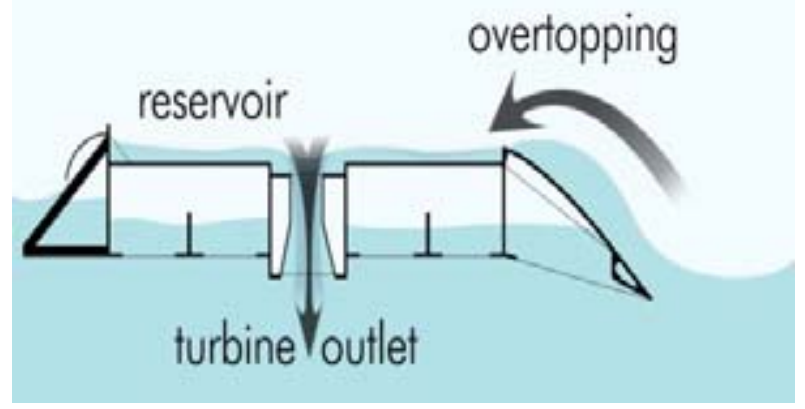

Figure 2 - Overtopping Wave Terminator Schematic.
The Pelamis wave device is a good example of an attenuator. In the Pelamis, waves induce angular deflections between three joints in both vertical and lateral directions. Motions are resisted by hydraulic systems in each module that covert hydraulic flow and pressures to electricity.

In overtopping terminators, the wave is first concentrated by wings and then focused toward a central reservoir. The amplified waves surge 
up a ramp and fill a reservoir at a level above sea level. The reservoir drains down through a hydro-electric type turbine device where electricity is generated. (see Figure 2).

Oscillating water column (OWC) terminators use wave motion to trap a volume of air and compress it in a closed chamber where it is exhausted at high velocities through a specialized ducted air turbine device. The kinetic energy of the moving air is converted to electricity. When the wave recedes, the airflow fills the chamber generating a second burst of energy. Conversion efficiencies of OWC air turbine device can be quite high because the flow must pass through the

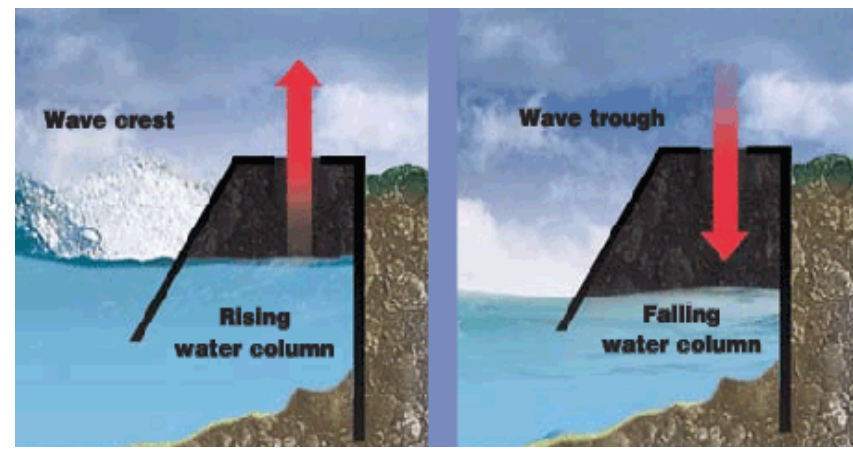

Figure 3 - Oscillating Water Column Wave Terminator Schematic. turbine unlike a free stream wind turbine (see Figure 3).

Although there are some devices under development for river and ocean currents, tidal turbines are the most common water current devices. The main difference between tidal and river/ocean current devices is that river and ocean currents flow in a single direction while tidal turbines reverse flow direction four times per day for ebb and flow cycles.

Many of the marine technology designs resemble wind turbine technology, but marine technologies must account for reversing flow, cavitation, and underwater marine material performance. Common rotor designs are either axial flow (similar to modern horizontal-axis wind turbines) or cross flow (similar to early vertical-axis wind turbines). Axial flow turbines must be physically oriented in the direction of flow while cross flow turbines can operate with flow from any direction. There are also several designs that incorporate shrouds around the outer diameter of the rotor. Shrouds can help incrementally improve hydrodynamic performance and may provide some environmental protection, but their benefits have not yet been proven. In at least one design, the shroud serves as part of the stationary part of the generator [18]. Shrouded rotors were rejected by the wind energy industry at an early stage because they were not cost effective, but because of the smaller size of water current converters and the higher density of water, the effectiveness of shrouds will need to be reevaluated.

Ocean current devices are primarily designed for open ocean currents and can provide continuous base-load power because of the nearly constant unidirectional current flow. The most notable resource for the United States is the Gulf Stream off the coast of Miami, Florida, which is estimated to have an energy extraction potential of $10 \mathrm{GW}$ at full build-out [12]. Aquantis LLC estimates they can install 7.5 GW of ocean current devices at this site [19] that could supply almost continuous power totaling $39.9 \mathrm{TWh} / \mathrm{yr}$ annually, which is equal to $17.7 \%$ of Florida's 2006 electricity usage [2]. Some environmental concerns exist about cumulative impacts of this technology on the circulation of the Gulf Stream and its affect on marine life. Proprietary studies performed by Aquantis and Florida Atlantic University show no significant impacts, but it is likely that further studies will be needed to satisfy all concerns. 


\section{Summary of Research and Development Needs}

Without substantial research and development, the marine renewable energy industry cannot easily reach its commercial goals. An R\&D focused plan to help the marine energy industry mature is underway in the United Kingdom [20,21]. Technology developers will have R\&D priorities that will be dependent on device-specific criteria. Some of this research might be best conducted in the private sector, but typically the need to attract commercial capital will prevent expensive in-depth R\&D studies and most of this information will not become publically available. The research needs described below are intended to be opportunities for a public sector R\&D effort that would have generic value to the industry and would collectively serve to accelerate the maturity of marine energy systems in the United States. This list is not exhaustive and will need to be modified as new information is obtained.

Design Basis and Evaluation: There is currently very little basis for the technical evaluation, design, or assessment of the various technology types. Although each device type could have merit in its own right, the industry does not have accepted and validated design tools and simulation models to guide the rapid increase of new technology concepts. Models will be needed to predict loads, dynamic behavior, power conversion and energy performance, fatigue, turbulence and flow characteristics, and device impact on the surrounding environment.

Moreover, because there are multiple concepts employing substantially different physical energy conversion principals, many different models will be required. While technology developers will develop their own physical models and will tend to hold these tools proprietary, third party evaluators will need complimentary tools to check the viability of various ideas. All these analytical design tools will need to be validated with experimental data from field experiments in order to gain confidence that they can predict the intended behavior. Ideally, these tests would be conducted with enough transparency that resource, regulatory, and research centers can use the data. This will be particularly important for certification of marine energy systems with respect to the establishment of public safety criteria.

Regulatory and Environmental: In general, marine energy systems will have to be at a higher state of maturity than wind energy systems in the early stages of development in the early 1980's, because siting will take place on public waterways and oceans where there will be a higher level of scrutiny over design function and performance, and a lower tolerance for failures. Any developer today could attest to the costly and timely process that is currently imposed upon the deployment of full-scale prototypes. This is largely due to deeply entrenched regulatory paradigms from the conventional hydro-electric industry, which were designed to limit or deter construction of new dams and impoundments but are now hindering the development of new clean energy technologies. Resource and regulatory agencies would cite the high degree of uncertainty associated with these technologies and, in particular, the potential cumulative impacts. However, imposing high-cost barriers to prototype deployments only discourages further deployment and prevents us from assessing the actual risk associated with the technologies.

All would agree that actual field data is needed to evaluate the real environmental impacts and develop a balanced regulatory framework. Before an informed and balanced strategy can be developed, detailed monitoring of the first installations by third party evaluators must be 
conducted with the goal of assessing the ecological risk associated with each technology-type and to help establish mitigation strategies. When new scientific findings become available, regulators must be flexible enough to adapt their rules.

Technology developers do not have additional resources or objectivity to embark on such monitoring campaigns, to make the uniform judgments about what should be measured, or to make the necessary interpretations of the data. Field data collection should be encouraged and supported through strong government leadership. Several countries in Europe have already established monitoring protocols for prototype deployments, and through our international collaborations, some of the uncertainty can be reduced quickly.

Experience from wind energy has taught us that seemingly small environmental consequences that are ignored during the early stages of development can lead to unfounded long-term negative public perceptions that are more difficult to dismiss if they are not addressed proactively. A good example is noise. Wind turbines are quiet compared to other common machinery, but because some early wind machines were loud, many people still perceive wind turbines to be obnoxious noise makers.

Resource Assessment Needs: We know that the global resources for marine renewable energy and new hydropower technologies are significant and can provide regional solutions to mitigate green house gases and head off energy shortfalls. For the United States, the resource has been partially estimated by EPRI and others, but much work is still needed. First, the resource assessment methodology must be consistent with respect to other technologies (e.g. wind) so that comparisons can be readily made. A uniform methodology for assessing all resource areas must be developed.

Next, comprehensive resource assessments should be conducted. For wave energy, the current resource estimates have a higher degree of confidence than for tidal energy where only the major inlets and estuaries with known tidal flux have been assessed with reasonable detail. Tidal and ocean current assessments are more difficult and may require more on-site measurements to fully characterize each location [3].

One of the more challenging steps will be to determine the true extraction potential for the resources, taking into consideration technology or device type, proximity to load, and local environmental and human use concerns. Currently, extraction-limits are simple educated guesses made by experts, but have not been vetted through scientific models and public acceptance.

\section{Potential Contribution of NREL}

Although marine renewable energy concepts date back several decades, in the last 10 years we have seen an explosion of interest in the technology. According to the International Energy Agency (IEA), the number of marine renewable technology companies worldwide grew from 35 in 2003 to 81 in 2006 [22]. NREL has been tracking wave and tidal energy with the U.S. Department of Energy since 1999 and has been a member of the IEA Ocean Energy Systems 
Executive Committee (IEA-OES ExCo) since 2004. NREL is currently technical administrator and founder of the International Electrotechnical Commission's (IEC) U.S. Technical Advisory Group to develop standards for the wave and tidal energy industry under the newly formed IEC TC114 international committee. These efforts have led to strong working relationships with regulatory agencies, industry trade groups, and technology companies. NREL's 30 years of leadership and expertise in the development of a wide range of renewable energy technology provides a firm basis for continued marine energy technology leadership.

Some examples of these synergies include:

- Wave and water current will have modular multiple-device arrays that are similar to wind farms and solar arrays.

- Renewable energy grid integration issues are similar (i.e. remote power generation, variable resources, and modular power production).

- Tidal turbines operate on the same principles as wind turbine rotors.

- Modeling fluid flow through a wave or water current turbine array will use similar methods as wind turbine array models.

- The design environment for ocean devices (e.g. extreme weather events, fatigue loading) will be defined and standardized using similar methods.

- Regulatory and siting have overlapping issues and responsibilities (e.g. the Federal Energy Regulatory Commission and Minerals Management Service have authority over offshore wind and marine energy projects)

- Ocean engineering requirements and logistics for marine energy systems are similar to offshore wind.

- Maintenance infrastructure requirements will be similar to offshore wind.

- The established GIS wind energy resource database can be expanded for marine renewable energy.

- Future innovations may allow some wind, wave, and solar facilities to be co-located in order to share infrastructure such as grid cables and foundations.

Although NREL is uniquely positioned to provide third party marine technology integration, evaluation, and technical leadership, technology success will depend on the innovations and efforts of multiple industry technology developers and university research centers where oceanbased testing and demonstration, and deployment can occur with lower risk and greater speed.

\section{Conclusions}

In the past decade, new technologies have been introduced to harness the energy of the oceans waves, currents, and tides. Nearly 100 companies worldwide have joined this effort but most companies struggle to deploy their first prototypes and not all can be funded from the public sector. A viable strategy to help mature the marine renewable energy industry is needed. One approach is to characterize technology status, performance, limits, and cost, and to develop and validate design tools and standards to facilitate a fair and equitable means for funding the most promising technologies. Performance, cost, and reliability metrics should be established to guide the process. New ocean testing facilities should be developed to facilitate rapid prototype 
deployment and testing. Finally, international cooperation can accelerate the development and to achieve the critical deployment capacity needed to bridge the gap from prototype to commercial maturity. Marine energy resources have global significance and should be developed as part of a diverse clean energy portfolio that will be necessary to reach expected future carbon reduction targets. No single energy source will be able to achieve these reductions independently, and these resources can make a significant contribution.

\section{References}

1. Arvizu, D. "Renewable Energy Technology Opportunities: Responding to Global Energy Challenges", Presentation at Sustainability Forum, February 28, 2007.

2. Energy Information Agency Web site; http://www.eia.doe.gov/emeu/states/_seds.html

3. Bedard, R. et al, "Ocean Wave and In-stream "Hydrokinetic" Energy Resources of the United States" Hydrovision Proceedings, Sacramento, CA, July 2008.

4. EPRI Ocean Energy Website, http://oceanenergy.epri.com/waveenergy.html

5. Hagerman, G. "Southern New England Wave Energy Resource Potential” EPRI, March 2001 ,

6. Hagerman, G. "Wave Energy Resource and Technology Assessment for Coastal North Carolina”, EPRI, 1988,.

7. Hagerman, G. "Wave Energy Resource and Economic Assessment for the State of Hawaii", EPRI, June 1992.

8. Kane, M.; Beyenne, A.; Previsic, M.; "California Small Hydropower and Ocean Wave Energy Resources” EPRI, May 2005.

9. EPRI Ocean Energy Website, http://oceanenergy.epri.com/streamenergy.html, EPRI TP001 Resource Estimation Methodology Report.

10. EPRI Ocean Energy Website, http://oceanenergy.epri.com/streamenergy.html, EPRI TP003 Site Survey Reports.

11. EPRI Ocean Energy Website, http://oceanenergy.epri.com/streamenergy.html, EPRI TP006 Feasibility Study Reports.

12. Lissaman \& Rackey, "Coriolis Program: A Review of the Status of the Ocean Turbine Energy System”, AeroVironment, 1979.

13. Miller et al. "Allocation of Kinetic Hydro Energy Conversion Systems (KHECS) in USA Drainage Basins", NYU, NYUDAS 86-151, Aug 1986

14. Bedard, R. "Economic \& Social Benefits from Wave Energy Conversion Marine Technology", Electric Power Research Institute, Marine Technology Society Journal, Fall, 2007.

15. "Ocean Energy In Ireland, An Ocean Strategy for Ireland submitted to the Department of Communications" Marine and Natural Resources, Sustainable Energy Ireland, October 2005

16. Hagerman, G. "Wave Power" Encyclopedia of Energy Technology and the Environment, Volume Set 4, John Wiley 7 Sons, Inc, 1995.

17. Khan J., Bhuyan, G. and Moshref, A. “An Assessment of Variable Characteristics of the Pacific Northwest Region's Wave and Tidal Current Power Resources, and their Interaction with Electricity Demand \& Implications for Large Scale Development Scenarios for the Region - Phase 1" Report No: 17458-21-00 (Rep 3), Prepared for 
Bonneville Power Administration (BPA), British Columbia Hydro (BCH), British Columbia Transmission Corporation (BCTC), January 2008.

18. Website for openhydro http://www.openhydro.com/home.html

19. Personal conversions with Aquantis; Chris Greico.

20. UKERC Marine (Wave and Tidal Current) Renewable Energy Technology Roadmap, University of Edinburgh, Accessed April 28, 2008. http://ukerc.rl.ac.uk/Roadmaps/Marine/Tech_roadmap_summary\%20HJMWMM.pdf

21. SUPERGEN Marine Energy Research, Full Report, University of Edinburgh, Oct 2007.

22. "Review and analysis of ocean energy systems development and supporting policies" A report by AEA Energy \& Environment on the behalf of Sustainable Energy Ireland for the IEA’s Implementing Agreement on Ocean Energy Systems, 28th June 2006. 


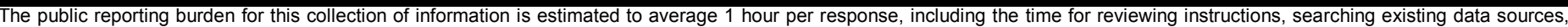

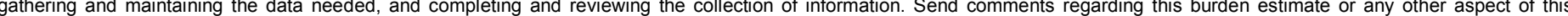

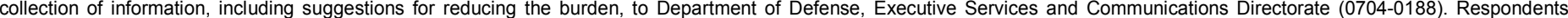

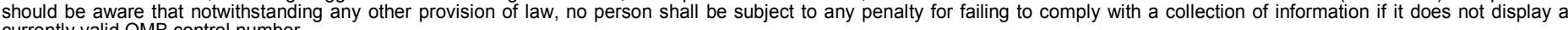
currently valid OMB control number.

PLEASE DO NOT RETURN YOUR FORM TO THE ABOVE ORGANIZATION.

\section{REPORT DATE (DD-MM-YYYY) August 2008 \\ 2. REPORT TYPE Technical Report}

4. TITLE AND SUBTITLE

Status of Wave and Tidal Power Technologies for the United States
3. DATES COVERED (From - To) 5a. CONTRACT NUMBER

DE-AC36-99-GO10337

5b. GRANT NUMBER

5c. PROGRAM ELEMENT NUMBER

6. AUTHOR(S)

W. Musial

5d. PROJECT NUMBER

NREL/TP-500-43240

5e. TASK NUMBER
7. PERFORMING ORGANIZATION NAME(S) AND ADDRESS(ES)

National Renewable Energy Laboratory

1617 Cole Blvd.

Golden, CO 80401-3393
8. PERFORMING ORGANIZATION REPORT NUMBER

NREL/ TP-500-43240

9. SPONSORING/MONITORING AGENCY NAME(S) AND ADDRESS(ES)

10. SPONSOR/MONITOR'S ACRONYM(S) NREL

11. SPONSORING/MONITORING AGENCY REPORT NUMBER

\section{DISTRIBUTION AVAILABILITY STATEMENT}

National Technical Information Service

U.S. Department of Commerce

5285 Port Royal Road

Springfield, VA 22161

\section{SUPPLEMENTARY NOTES}

14. ABSTRACT (Maximum 200 Words)

This paper presents the status of marine applications for renewable energy as of 2008 from a U.S. perspective.

Technologies examined include wave, tidal, and ocean current energy extraction devices.

\section{SUBJECT TERMS}

ocean current technologies; wave energy technologies; tidal energy technologies; renewable energy

\begin{tabular}{l}
\hline \multicolumn{3}{|l|}{ 16. SECURITY CLASSIFICATION OF: } \\
\begin{tabular}{|l|l|l|}
\hline a. REPORT & b. ABSTRACT & c. THIS PAGE \\
Unclassified & Unclassified & Unclassified \\
& & \\
\hline
\end{tabular}
\end{tabular}

17. LIMITATION
OF ABSTRACT
UL

18. NUMBER
OF PAGES

19a. NAME OF RESPONSIBLE PERSON

19b. TELEPONE NUMBER (Include area code) 